\title{
Noninfectious inflammatory reaction to a gold weight eyelid implant: A case report and literature review
}

\author{
Yiannis lordanous MD¹, Brian Evans MD $^{2}$
}

Y Iordanous, B Evans. Noninfectious inflammatory reaction to a gold weight eyelid implant: A case report and literature review. Can J Plast Surg 2012;20(3):199-200.

Upper eyelid loading with a gold weight is a generally well-tolerated procedure that helps reduce corneal exposure in patients with lagophthalmos. Complications of this procedure are infrequent. The authors present a rare case of a noninfectious inflammatory response to an eyelid gold weight implant in a 48-year-old woman and summarize all previously published cases. This particular patient presented with incomplete left eyelid closure secondary to a trauma. After having a gold weight inserted into her eyelid to improve closure, she returned with edema and erythema of the eyelid. The inflammation did not respond to oral antibiotics; however, oral steroid therapy resulted in prompt resolution of her symptoms. Her symptoms recurred after discontinuing steroid use and she subsequently required removal of her gold weight implant for permanent resolution of her eyelid inflammation. Although rare, this reaction poses a serious management issue, because it does not respond to antibiotics or short-term steroid use and, in most cases, requires removal of the gold implant.

Key Words: Gold weight eyelid implant; Inflammatory reaction; Oculoplastics

U pper eyelid loading with a gold weight was first described in the English-language literature in 1966 (1), and is widely used to reduce corneal exposure secondary to facial nerve paralysis. This procedure is quite successful in improving eyelid closure and providing corneal protection. Although infrequent, various complications have been reported, including migration and extrusion of the implant $(2,3)$, infection (4,5), induced astigmatism (6) and contact dermatitis (7). The present article describes a rare case of a noninfectious inflammatory reaction to a gold weight eyelid implant and summarizes the current literature describing this complication.

\section{CASE PRESENTATION}

A 48-year-old woman was referred to the Division of Plastic Surgery (University Hospital, London, Ontario) for assessment of incomplete closure of her left upper eyelid. The patient was involved in a motor vehicle collision at the age of 18 , which resulted in serious head trauma. She claimed to have had poor closure of the left eye since that time. She also complained of intermittent difficulty focusing her left eye. She was using lubricating eye drops for symptomatic relief. Her medical history included hypertension and Crohn's disease. She denied any allergies and, in particular, noted no skin reactions to gold jewelry.

Her ophthalmological examination revealed best corrected visual acuity of 20/25 bilaterally. Her intraocular pressure was $17 \mathrm{mmHg}$ bilaterally. No corneal abnormalities were noted on anterior segment examination. Her facial nerve function was normal on the right side, and she had poor lid closure of the left eye with blinking. However, when asked to forcefully close the left eye, her closure was complete and strong.

Treatment options for the incomplete eyelid closure were discussed with the patient, which included continuing conservative management with ocular lubrication or surgical intervention with gold weight insertion into the upper eyelid. After a discussion of the risks and benefits, the patient decided to have a gold weight inserted into her left upper

\author{
Une réaction inflammatoire non infectieuse à \\ l'implant d'une plaque d'or sur la paupière : rapport \\ de cas et analyse bibliographique
}

L'alourdissement de la paupière supérieure par une plaque d'or est une intervention généralement bien tolérée qui contribue à réduire l'exposition de la cornée chez des patients ayant une lagophtalmie. Les complications de cette intervention sont rares. Les auteurs présentent un rare cas de réponse inflammatoire non infectieuse à l'implant d'une plaque d'or chez une femme de 48 ans et résument tous les cas déjà publiés. La paupière gauche de cette patient ene se fermait pas complètement en raison d'un traumatisme. Après qu'une plaque d'or fût insérée dans sa paupière pour en améliorer la fermeture, elle a consulté de nouveau en raison d'un œè̀me et d'un érythème de la paupière. L'inflammation n'a pas répondu aux antibiotiques par voie orale, mais la stéroïdothérapie orale a favorisé une résolution rapide des symptômes, qui se sont manifestés de nouveau après l'arrêt de ce médicament. Il a fallu retirer la plaque d'or pour assurer une résolution permanente de l'inflammation de la paupière. Bien qu'elle soit rare, cette réaction pose un grave problème de prise en charge, car elle ne répond pas aux antibiotiques ou aux stéroïdes à court terme, sans compter que dans la plupart des cas, il faut retirer la plaque d'or.

eyelid. A gold weight (1 g) was selected to ensure proper lid closure without creating ptosis.

The patient was seen in clinic one week later and was found to have good lid closure with the incision healing well. She was reexamined six weeks later (seven weeks postoperatively). At that time, she complained of persistent swelling of the upper lid (Figures 1A and 1B). There was no drainage noted from the lid or eye, and she had no systemic signs of infection. She was started on a course of oral cefalexin. She was seen in clinic one week later and noted ongoing swelling that had not improved despite antibiotic therapy. Her lid closure was adequate at that time, but she had significant upper lid swelling. The gold weight was noted to be in its original position, and there was no evidence of migration or extrusion. She was then started on a 12-day course of prednisone, and scheduled to be seen in clinic two weeks later. At her two-week follow-up (approximately 10 weeks postoperatively), the swelling subsided completely with prednisone use. Within a few days of stopping the prednisone, her swelling recurred. She was then started on a one-month course of prednisone. Her swelling resolved promptly; however, after completing the monthlong course of prednisone the swelling recurred.

It was decided that the risk of long-term steroid therapy outweighed the benefit of keeping the gold weight in place and the patient opted to have it removed. She was followed postoperatively and we found that the swelling resolved over the course of a few weeks. She opted for no further surgical intervention and continued using lubricating eye drops to manage her incomplete lid closure.

\section{DISCUSSION}

Gold weight implantation into an eyelid has been very successful for correcting exposure keratitis in cases of lagophthalmos. This procedure can be performed under local anesthetic and is not technically complex. Although very infrequent, several complications have been 

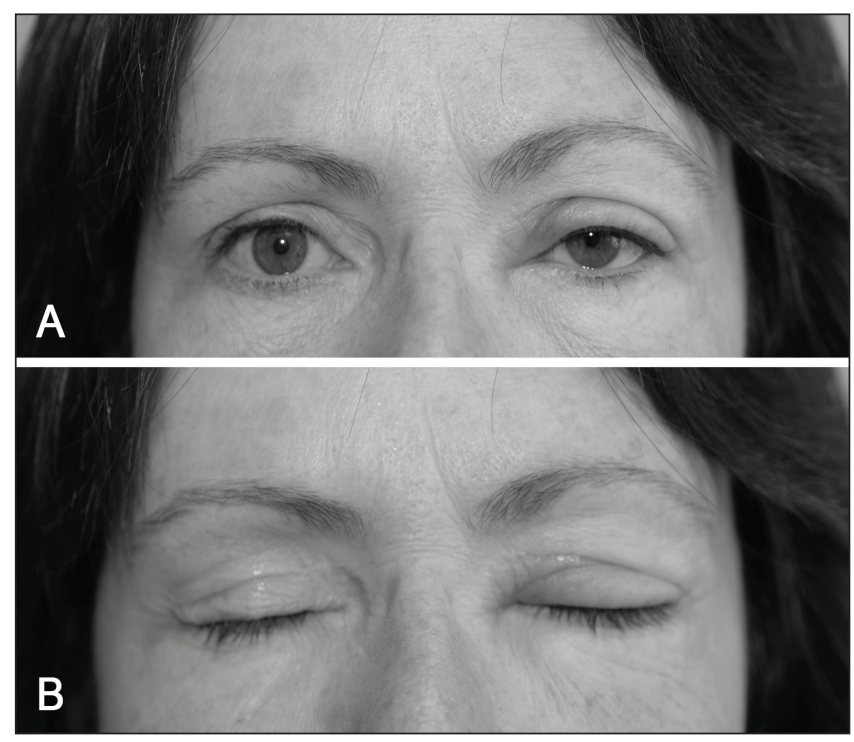

Figure 1) Photographs of a 48-year-old woman seven weeks after gold weight implantation (left upper eyelid; panel A). Erythema and edema of the left upper eyelid is noted. Excellent lid closure was maintained despite the inflammatory reaction (panel B)

noted in previous studies. Migration and extrusion $(2,3)$ were reported more frequently before changes in surgical technique and improvement in gold weight design. Infection (4,5), induced astigmatism (6) and contact dermatitis (7) are also uncommon complications that can occur.

Another rare complication of this procedure is a noninfectious inflammatory reaction to the gold weight. We have described one patient who experienced this reaction at our centre. Our literature search revealed only three articles that describe this complication, and they report on a total of six patients $(5,8,9)$. Although a rare complication, when it occurs, the outcomes tend to be poor, because most patients will require removal of their implant. Of the six patients described in the literature, five needed to have their implants removed after conservative management failed $(5,8,9)$. The subject in our case also failed conservative therapy and required subsequent removal of her gold weight.

The frequency with which these inflammatory reactions occur is unclear. One retrospective review found two such cases, out of 62 procedures performed, over a nine-year period (8). Another study reported one case over a 10 -year period at a single institution (5). These reactions may occur more frequently than the six previous cases in the literature suggest. Because many studies examining complications of gold weight eyelid loading are retrospective, mild or self-limited cases of inflammatory reactions may have been missed.

Based on the current available literature, it appears that these inflammatory reactions are detected as early as one week postoperatively and as late as 12 weeks. The cause of this reaction, however, is not certain. Previous studies have examined tissue samples taken from patients who had their gold weights removed $(5,8,9)$. Based on pathological specimens, Doyle et al (8) suggested that this complication is mediated by a type IV hypersensitivity reaction to gold. One of the two patients in that case series tested positive for a gold allergy on skin testing; however, the other patient refused allergy testing. Bair et al (9) found that one of the three patients in their case series had a presumed gold allergy, because she was unable to wear gold jewelry; however, none of those patients were formally patch-tested. Our patient did not have a known gold allergy and was not formally tested.
Management was similar among all the previously reported patients. In a series of three patients, oral antibiotics were first-line therapy for individuals who presented with erythema and edema of the eyelid (9). All patients failed to respond to antibiotics, which led to either corticosteroid use (topical, oral or subcutaneous injection) or removal of the implant. Only one patient retained their implant, and this was after a corticosteroid injection into the eyelid. In another set of two patients, topical and oral antibiotics were started when an inflammatory reaction was suspected (8). Again, both of these patients failed initial management and only experienced temporary resolution with topical steroids. Both patients had their implants removed. Another case report described a single patient who experienced an inflammatory reaction, as well as trichiasis and entropion of the upper eyelid (5). This patient was treated with oral and topical antibiotics, and experienced no symptomatic improvement; he subsequently had his gold weight removed. Our patient followed a similar course to the others previously described. Oral antibiotics were used first, with no resolution of symptoms. This was followed by oral steroids, which temporarily resolved her symptoms. She eventually required removal of her gold weight implant for permanent resolution of her inflammation.

\section{CONCLUSIONS}

A noninfectious inflammatory response to an eyelid gold weight is an uncommon complication of an otherwise quite effective procedure. It has been detected as early as one week postoperatively, making close follow-up important. Studies suggest that the mechanism of this reaction is type IV hypersensitivity; thus, one should explore the possibility of a gold allergy preoperatively with a thorough history and patch testing if necessary (8). Most patients with this complication will eventually require removal of their gold implant, because antibiotics are ineffective, and both topical and systemic steroids do not provide permanent resolution of symptoms. There is a single case of a patient having full resolution of inflammation after steroid injection into the affected eyelid; this therapy should be considered if one encounters this inflammatory reaction (9). Given the poor response to antibiotics and steroids, one may consider removing the gold weight rather than continuing with repeated courses of medications over an extended period of time.

\section{REFERENCES}

1. Smellie GD. Restoration of the blinking reflex in facial palsy by a simple lid-loading operation. Br J Plast Surg 1966;19:279-83.

2. Pickford MA, Scamp T, Harrison DH. Morbidity after gold weight insertion into the upper lid in facial palsy. Br J Plast Surg 1992;45:460-4.

3. Harrisberg BP, Singh RP, Croxson GR, Taylor RF. Long-term outcome of gold weights in patients with facial nerve palsy. Otol Neurotol 2001;22:397-400.

4. Kelly SA, Sharpe DT. Gold eyelid weights in patients with facial palsy: A patient review. Plast Reconstr Surg 1992;89:436-40.

5. Dinces EA, Mauriello J, Kwartler JA, Franklin M. Complications of gold weight eyelid implants for treatment of fifth and seventh nerve paralysis. Laryngoscope 1997;107:1617-22.

6. Mavrikakis I, Beckingsale P, Lee E, Riaz Y, Brittain P. Changes in corneal topography with upper eyelid gold weight implants. Ophthal Plast Reconstr Surg 2006;22:331-4.

7. Bjorkner B, Bruze M, Moller H, Salemark L. Allergic contact dermatitis as a complication of lid loading with gold implants. Dermatitis 2008;19:148-53.

8. Doyle E, Mavrikakis I, Lee EJ, Emerson R, Rainey AJ, Brittain GP. Type IV hypersensitivity reactions to upper lid gold weight implants is patch testing necessary? Orbit 2005;24:205-10.

9. Bair RL, Harris GJ, Lyon DV, Komorowski RA. Noninfectious inflammatory response to gold weight eyelid implants. Ophthal Plast Reconstr Surg 1995;11:209-14. 